\title{
Spatial Properties of the Amplitude Fading of Continuous HF Radio Waves ${ }^{1}$
}

\author{
John Ames \\ Contribution From the Radioscience Laboratory, Stanford University, Stanford, Calif.
}

(Received July 22, 1964)

\begin{abstract}
Amplitude fading of $17 \mathrm{Mc} / \mathrm{s}$ CW signals is observed on 12 dipole antennas evenly spaced in two perpendicular rows each about $300 \mathrm{~m}$ long. The signals are ionospherically propagated over approximately east-west 20 to $35 \mathrm{deg} \mathrm{N}$ latitude paths of 1840, 3741, and $5724 \mathrm{~km}$. The number of hops on the two shorter paths is determined by oblique, stepfrequency soundings.

Periodic spatial fading patterns consisting of approximately straight, parallel nulls exist 33 percent of the time on the $1840 \mathrm{~km}$ signal and 10 percent of the time on the 5740 $\mathrm{km}$ signal. Mean null spacing on the $3741 \mathrm{~km}$ signal varies from $1.4 \mathrm{~km}$ during periods of $1-F$ propagation to $0.4 \mathrm{~km}$ during periods of $3-F$ propagation.

The peciodic fading patterns are shown to be caused by multipath interference between rays. A tendency for the nulls to have a diagonal position, with respect to the great circle connecting the transmitter and receiver, is found to be a result of small azimuthal ray deviations caused by small transverse ionospheric tilts.

During two magnetic storms the lateral ionospheric tilt over the 3741-km path appeared, from the fading pattern measurements, to be less than normal during the first $10 \mathrm{hr}$, and somewhat greater than normal during the remainder. During one of these storms the fading patterns were much more periodic than usual, implying that the random variations in ionization density were smaller than usual.

These results show that measurement of the direction of fading patterns on the ground is a sensitive technique for studying small ionospheric tilts. In addition, it appears that dual space-diversity reception, over paths where lateral ionospheric tilts of one predominant direction are encountered, can be optimized by spacing antennas along a line normal to the predominant null direction.
\end{abstract}

\section{Experimental Arrangements}

\subsection{Receiving Array}

The spatial distribution of radio-wave field strength was observed by means of a group of antennas (fig. 1) consisting of two perpendicular rows of horizontal dipoles, each tuned to $17.8 \mathrm{Mc} / \mathrm{s}$. One row of seven dipoles was on a line with a bearing: of $96 \mathrm{deg}$ east of north. The other row of five dipoles was perpendicular to the first. The individual antennas were $9 \mathrm{~m}$ (one-half wavelength) above ground and were spaced $61 \mathrm{~m}$ (3.6 wavelengths) center to center. Ground reflections would be expected to give such antennas a vertical sensitivity pattern consisting of a single broad lobe with a maximum response at $30 \mathrm{deg}$ and a 50 percent voltage response at $10 \mathrm{deg}$ above the horizon. During the course of the experiment an extra dipole was added between 6 and 7 , to facilitate interpreting very closely spaced fades.

\footnotetext{
1 Prepared under Office of Naval Research Contract Nonr-225(64), NR 088019 , and Advanced Research Projects Agency ARPA Order 196-63. The numerical computations and machine data plotting were, in part, subsidized by NSF grant GP 948.
}

2 Now at Granger Associates, 1601 California, Palo Alto, Calif.

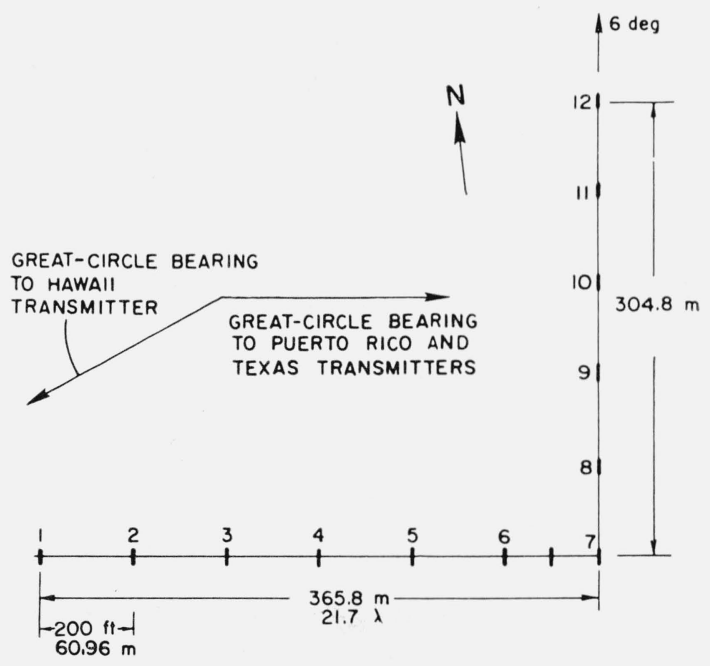

Figure 1. Plan view of fade-sampling array.

Individual coaxial cables connected each antenna to an electronic commutator in the receiver building. The commutator, consisting of diode gates driven by multivibrators, sampled each antenna in numerical 
order for 5 msec, repeating a cycle every 85 msec. The commutated signal then went to an $\mathrm{R}-390 \mathrm{~A}$ communications receiver with a bandwith of $2 \mathrm{kc} / \mathrm{s}$ and a modified AGC time constant of about 2 sec.

The IF output of the receiver modulated the beam intensity of an oscilloscope, the sweep of which was synchronized with the commutator cycle. When this intensity-modulated sweep was photographed by a film moving perpendicular to the trace at constant speed, a record such as figure 2 was produced. The dark regions correspond to signal minima, the light ones to signal maxima.

If a series of straight-line signal nulls moved across the array, the direction, spacing, and speed of the nulls can be obtained by measuring the times when adjacent fades crossed antennas 1, 7, and 12 . No quantitative measurement was made on the remaining antennas, although the information from them is essential to identify the presence of straight fades, their gross direction, and their spacing. The shape and motion of small-scale curved fades could in principle be deduced, but the reduction problem would be formidable and the results more difficult to interpret.

Data, as in figure 2, were recorded for approximately 20 -sec periods at 2 -min intervals throughout the day. The information describing two adjacent nulls out of each 2-min period was transcribed from the film onto punched cards by means of a film reader. The choice of which particular null pair to record was subjective, with the object being to pick a pair that was representative of that 20 -sec period and that was also clear enough to read accurately. After the data were on cards, they were analyzed by means of a computer program that yielded the direction $\Phi$, of the perpendicular to a null, the perpendicular spacing, $D$, along the ground between the nulls, the apparent velocity, $V$, of the nulls in the direction perpendicular to their length, and the single component fading rate, $F$, which is the fading rate that would be observed on a single antenna if the measured pattern were the only fading present. The null configuration deduced from figure 2 is shown in figure 3.

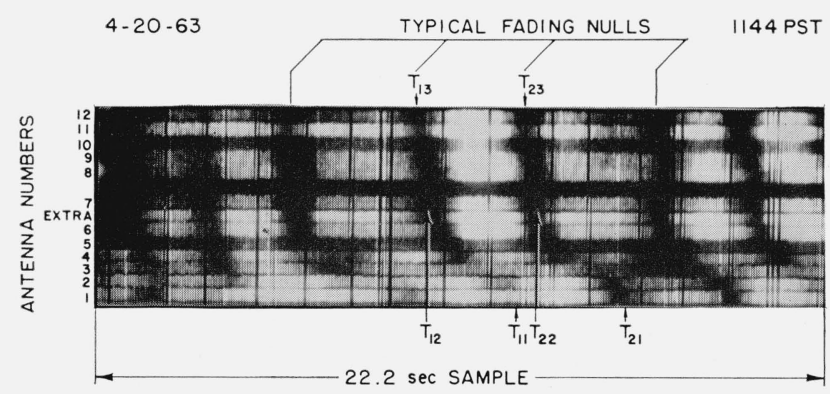

Figure 2. Typical record from fade-sampling array.

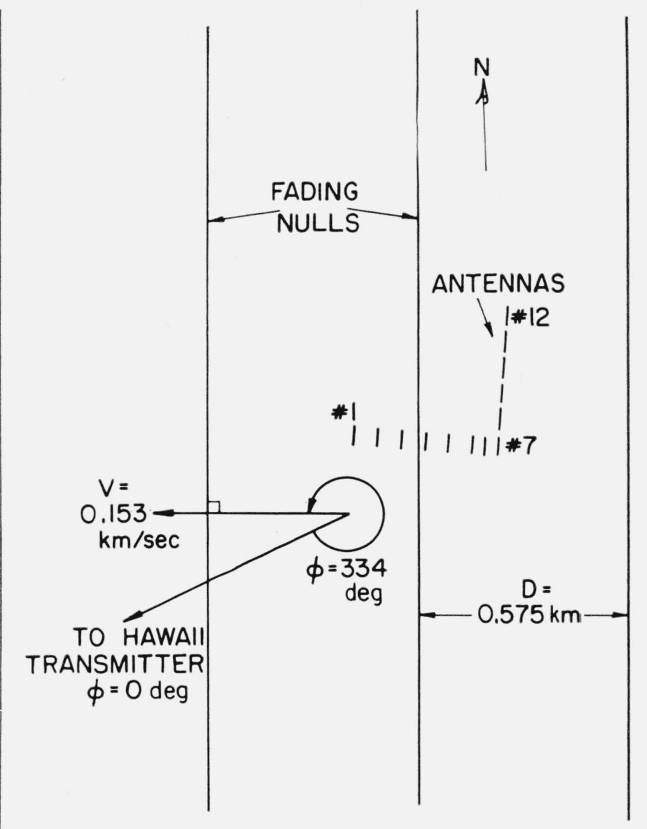

Figure 3. Plan view of null configuration deduced from figure 2 .

\subsection{Transmissions and Paths}

Three paths were studied during the course of the experiment. Table 1 contains the parameters of the CW transmissions.

TABLE 1. CW transmission parameters

\begin{tabular}{|c|c|c|c|c|c|c|}
\hline Path & $\begin{array}{l}\text { Great- } \\
\text { circle } \\
\text { bearing } \\
\text { from } \\
\text { Stanford }\end{array}$ & Range & $\begin{array}{c}\mathrm{CW} \\
\text { frequency }\end{array}$ & $\begin{array}{c}\mathrm{CW} \\
\text { power }\end{array}$ & $\begin{array}{l}\text { Height } \\
\text { of trans- } \\
\text { mitting } \\
\text { antenna }\end{array}$ & $\begin{array}{c}\text { Dates of } \\
\text { operation }\end{array}$ \\
\hline $\begin{array}{l}\text { Mayaguez, } \\
\text { P.R., to } \\
\text { Stanford, } \\
\text { Calif. }\end{array}$ & ${ }^{d e g}{ }_{96}$ & $\begin{array}{l}k m \\
5724\end{array}$ & $\begin{array}{c}M c / s \\
17.8825\end{array}$ & ${ }_{700}^{W}$ & $\begin{array}{l}m \\
13.5\end{array}$ & $\begin{array}{l}\text { May 14, } \\
\text { 1962, to } \\
\text { June 1, } \\
1962 .\end{array}$ \\
\hline $\begin{array}{l}\text { Pahoa, Hawaii, } \\
\text { to Stanford, } \\
\text { Calif. }\end{array}$ & 247 & 3741 & 17. 8625 & 700 & 21 & $\begin{array}{l}\text { Nov. 2, } \\
1962 \text {, to } \\
\text { June 8, } \\
1963 .\end{array}$ \\
\hline $\begin{array}{l}\text { Lubbock, Tex., } \\
\text { to Stanford, } \\
\text { Calif. }\end{array}$ & 96 & 1840 & 17. 7385 & $50-500$ & 15 & $\begin{array}{l}\text { Aug. 1, } \\
\text { 1963, to } \\
\text { Oct. } 23, \\
1963 .\end{array}$ \\
\hline
\end{tabular}

\subsection{Mode Identification}

Synchronized, oblique, ionosphere sounders were operated over the paths from Hawaii and Texas to Stanford in order to be able to identify the modes propagating at any given time. The sounder receiving antenna was $30 \mathrm{~m}$ high. It was therefore more sensitive to low angle rays than were the CW antennas. A typical oblique ionogram is shown in figure 4 . 


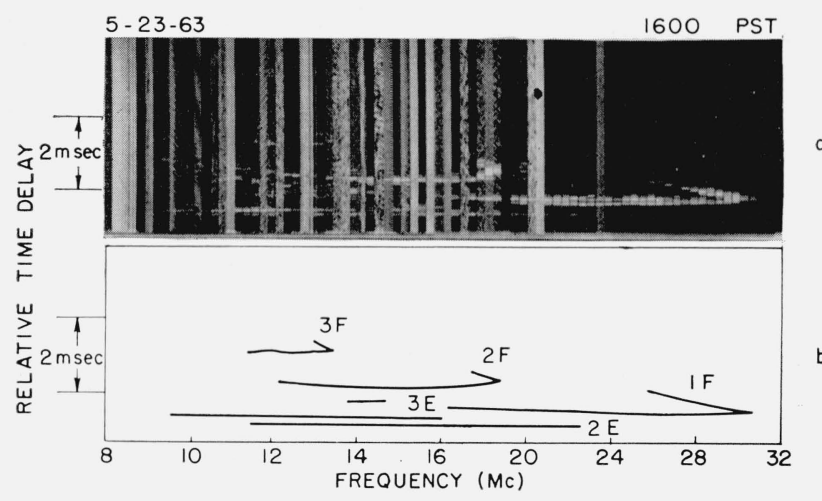

Figure 4. Typical oblique ionogram.

\section{Observations and Interpretations}

\subsection{Amount of Periodic Fading Observed}

\section{a. Definition of Periodicity}

Two semiobjective standards of periodicity are established. The fading patterns are considered "periodic" if they appear at least as regular as the samples in figure 5. The patterns are considered "measurable" if they appear as regular as the samples in figure 6. Though it is difficult to establish purely objective criteria for these categories, it is readily apparent that the "measurable" patterns in figure 6 show a greater degree of irregularity than the "periodic" ones of figure 5. It is equally clear that the "measurable" patterns exhibit enough tendency toward regularity for measurements made on appropriate adjacent fades to be characteristic of the fading during the sample period.

The samples of figure 7, though strictly speaking not completely random, do not have enough regularity to make meaningful pattern measurements. For example, adjacent nulls in the center frame on the left in figure 7 appear to be moving in opposite directions. The irregular patterns usually have sizes and shapes similar to the regular ones, indicating that they probably are a result of similar but more complex mechanisms, such as interference between
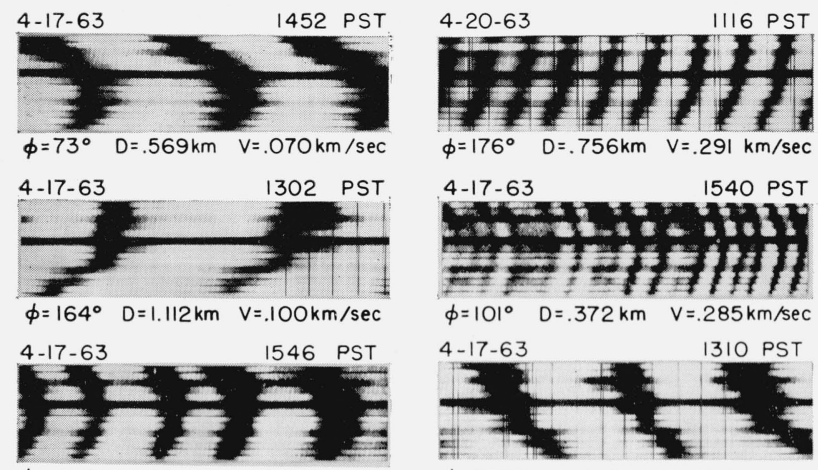

$\phi=109^{\circ} \quad D=1.078 \mathrm{~km} \quad V=.230 \mathrm{~km} / \mathrm{sec}$

Figure 5. Sample fading records showing "periodic" fading patterns.
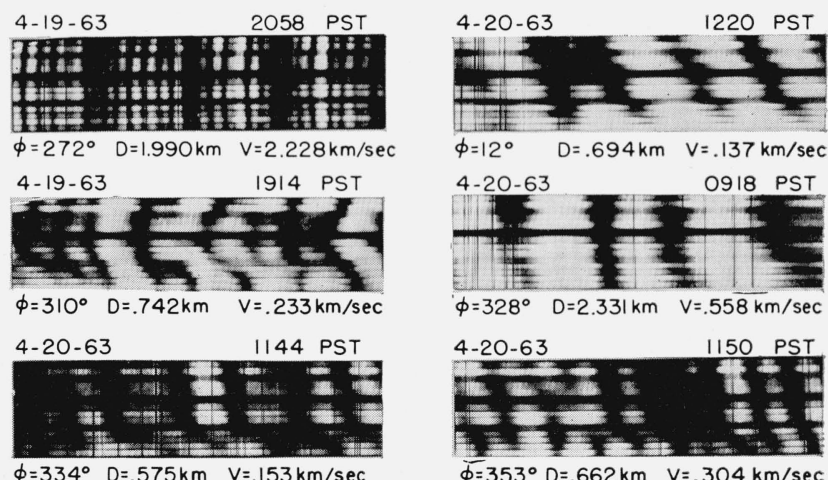

$\phi=12^{\circ} \quad D=.694 \mathrm{~km} \quad V=.137 \mathrm{~km} / \mathrm{sec}$

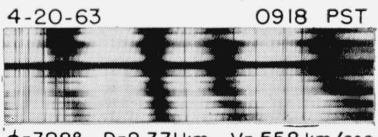

$\phi=328^{\circ} \quad D=2.331 \mathrm{~km} \quad V=.558 \mathrm{~km} / \mathrm{sec}$

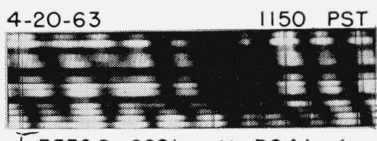

$\phi=353^{\circ} \mathrm{D}=.662 \mathrm{~km} \quad \mathrm{~V}=.304 \mathrm{~km} / \mathrm{sec}$

Figure 6. Sample fading records showing "measurable" fading patterns.
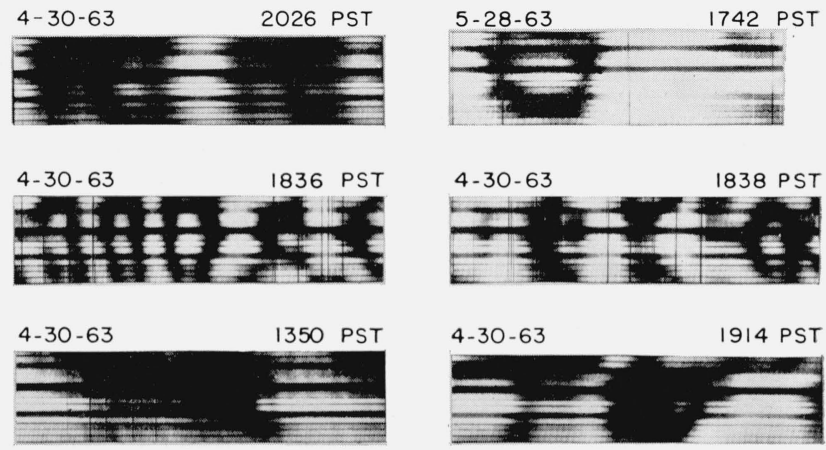

Figure 7. Sample fading records showing "random" or nonmeasurable patterns.

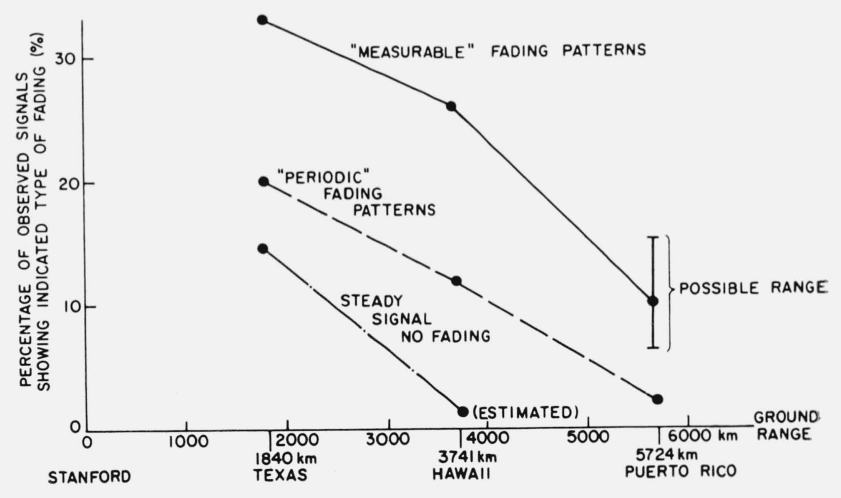

Figure 8. Periodicity of fading patterns as a function of path length.

three or more raypaths of comparable intensity, or between raypaths that have been subjected to random focusing or ion-density variations of sufficient magnitude to obscure their regularity.

\section{b. Dependence on Path Length}

The periodicity of the observed fading patterns decreases with path length, with "periodic" patterns present on 20 percent of the signals received from Texas but on only 2 percent of those from Puerto Rico. These results are shown in figure 8. Early 
in the course of the experiment, when the Puerto Rico data were being analyzed, a somewhat more flexible standard existed for the classification of patterns as "measurable," resulting in the range of uncertainty shown.

Consideration of the amount of electron density variation required to shift the phase of a ray one radian reveals that during periods of periodic fading patterns the random variation of electron density is about 0.0003 percent per second [Ames, 1964]. During periods of random fading patterns, the random fluctuations of electron density are greater than 0.003 percent per second.

\subsection{Correlation of Observed Fading Pattern Param- eters With Known Mode Configurations}

$$
\text { a. Theory }
$$

Equations (1), (2) and (3) describe the null spacing, $D$, and the orientation, $\Phi$, of fading patterns resulting from interference between coherent waves arriving with bearing angles $\theta_{1}$, and $\theta_{2}$, and elevation angles $\eta_{1}$, and $\eta_{2}$. $\theta$, like $\Phi$, the null angle, is defined as zero in the direction to the distant transmitter.

$$
\begin{gathered}
\Phi_{A}=-\tan ^{-1}\left[\frac{\cos \eta_{1} \cos \theta_{1}-\cos \eta_{2} \cos \theta_{2}}{\cos \eta_{1} \sin \theta_{1}-\cos \eta_{2} \sin \theta_{2}}\right]+\frac{\pi}{2} \\
\Phi_{B}=\Phi_{A}+\pi
\end{gathered}
$$

$$
D=\frac{\lambda}{\left[\begin{array}{c}
\sqrt{\left(\cos \eta_{1} \cos \theta_{1}-\cos \eta_{2} \cos \theta_{2}\right)^{2}} \\
+\left(\cos \eta_{1} \sin \theta_{1}-\cos \eta_{2} \sin \theta_{2}\right)^{2}
\end{array}\right]} .
$$

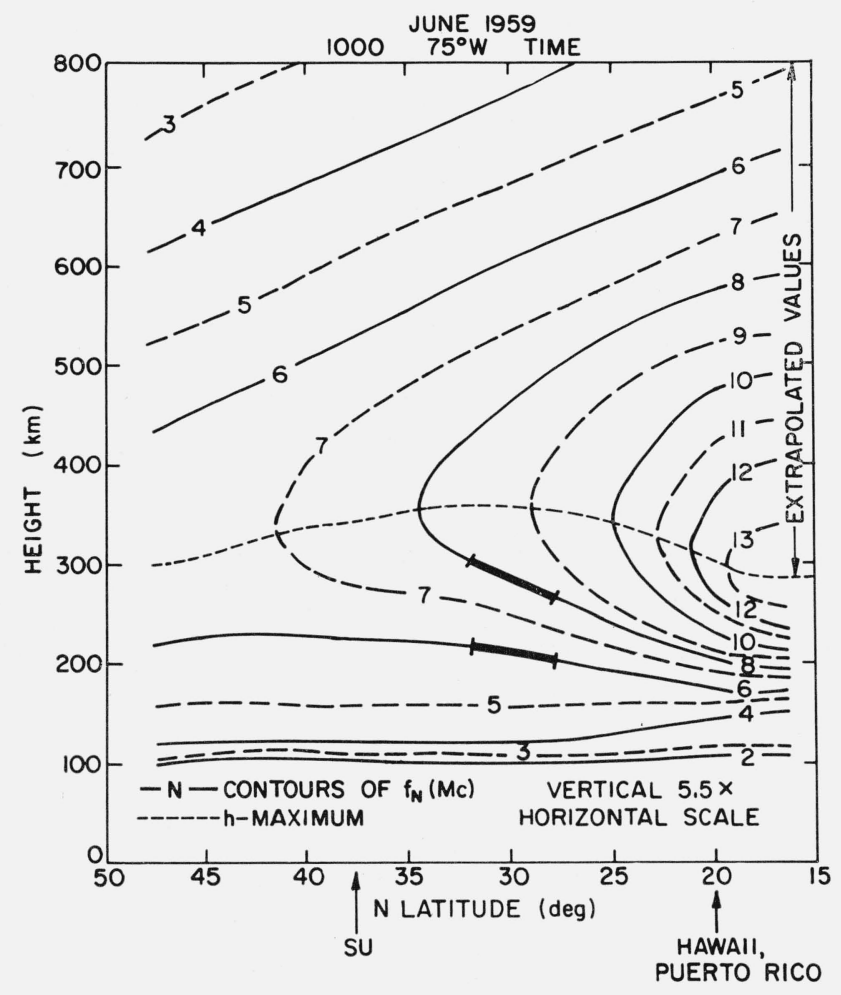

Figure 9. Representative daytime plot of ion-density contours.
The elevations, $\eta_{1}$ and $\eta_{2}$, of the different rays are estimated by means of digital ray tracings [Croft and Gregory, 963$]$.

The bearings are estimated by a consideration of lateral tilts in the ionosphere over the paths studied. Figure 9 shows typical heights of different electron density contours as a function of latitude, as observed by Wright, Wescott, and Brown [1961]. Note that at the latitude of the midpoint of the Hawaii to Stanford path, which follows, primarily, a west to east direction, the levels of constant electron density slope 2 or 3 deg downward toward the south. The same effect occurs on the Puerto Rico and Texas paths, which are actually closer to the longitude where the density contours were measured.

Figure 10 shows that rays making equal-angle reflections from such a tilted layer will appear, at the receiver, to have deviated toward regions in which the contours of constant electron density are at a relatively low altitude; that is, toward regions of high critical frequency. Thus, for signals arriving at Stanford from Hawaii, to the west, and from Puerto Rico and Texas, to the east, the rays will appear, at the receiver, to be deviated 1 or $2 \mathrm{deg}$ to the south of the true great circle. Rays experiencing: a greater number of reflections would be expected to show greater deviation as a consequence of the higher elevations reached by such rays.

Figure 11 shows in simplified form the effect of small ray deviations on interference fading patterns. Consider the two small spheres at the ends of the dumbbell to be separate rf energy sources such as rays from the 2 - and 3 -hop reflection points. If these sources have opposite phase, there will be a null in the plane midway between them. The line formed by the intersection of this null plane with the ground will be the null observed by antennas on the ground.

If both energy sources are in a vertical plane, the null at the ground will be perpendicular to the direction to the distant transmitter, as shown by the arrow. If the energy sources move laterally different distances so that they are no longer in a vertical plane, the tilted null plane will rotate about the axis shown by the dotted line, and the null at the ground will change direction. One can see that if rays arrive at a low angle very large changes in null direction will result from small lateral ray deviations.

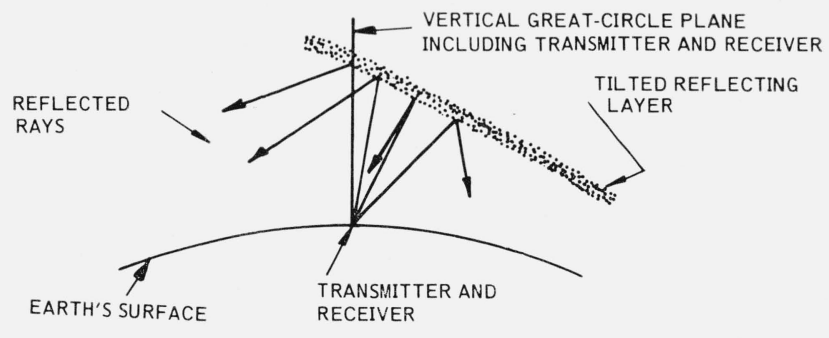

Figure 10. Illustration of ray deviation. 
Magneto-ionic (polarization) fading can effectively remove a particular ray for tens of seconds from the summation contributing to the CW signal [Hedlund and Edwards, 1958]. Consider, for example, a situation in which $1-F$ and $2-F$ horizontally polarized rays are interfering to form a periodic pattern. Since the antennas are horizontally polarized, if one of the rays becomes vertically polarized, the fading will cease, leaving a steady signal.

\section{b. Observations}

Hawaii data. Figure 12 shows a plot of calculated and observed fading patterns for the Hawaii signal during times when propagation was by 1,2 , and 3 $F$-region reflections as observed on oblique ionograms. Reference rays are assumed with elevations, $\eta$, of $2 \mathrm{deg}$ for $1-F, 14 \mathrm{deg}$ for $2-F$, and $22 \mathrm{deg}$ for $3-F$, and nominal bearings, $\theta=0$ deg. The rectangular coordinates represent the fading parameters, null spacing, and angle. The curved coordinates represent differences in elevation and bearing between the reference ray and another ray which could interfere to form the fading patterns described by the corresponding rectangular coordinates.

The most obvious characteristics of the data are that the null directions are concentrated in quadrants II and IV and that the null spacing decreases as the number of ionospheric reflections increases.

The concentration of null angles in quadrants II and IV implies that the values of $\Delta \theta$ and $\Delta \eta$ have the same sign. This would be expected for signals from. Hawaii because an apparent deviation to the south of the great circle corresponds to a positive value of $\Delta \theta$, and it is probable that rays reaching greater heights will suffer greater bearing deviations.

The decrease in null spacing with increasing ionospheric reflections is simply a result of the higher elevation angles of the higher order modes.

In view of the approximate 180-deg symmetry of the data, two centroids, shown as circled crosses, were calculated for each of the scatter plots of $D$ versus $\Phi$. The logarithmic $D$ scale makes the centroids appear slightly high and the scarcity of points on the $3-F$ plot (fig. 12c) makes the centroids in that case somewhat ambiguous. In addition, values of $D$ greater than $10 \mathrm{~km}$ were plotted as $10 \mathrm{~km}$ but the centroids were calculated using the full values.

A number of interesting additional phenomena, not all of which are understood, appear in the $D$ versus $\Phi$ scatter plots.

Tn figure $12 \mathrm{a}$ there are two quite symmetrical groups of points clustered about $\Phi=100 \mathrm{deg}$ and $\Phi=280 \mathrm{deg}$ with values of $D$ between 0.4 and $2.0 \mathrm{~km}$, corresponding to values of $\Delta \theta$ (bearing separation) of between 0.5 and $2.0 \mathrm{deg}$ and elevation separation, $\Delta \eta$, up to about $6 \mathrm{deg}$. These points probably correspond to interference between $1-F$ upper rays and either $1-F$ lower rays or $3-E$ rays.

There is another group of points in figure $12 \mathrm{a}$ with values of $\Phi$ between 330 and $360 \mathrm{deg}$ that is not balanced by a corresponding group near 180 deg.
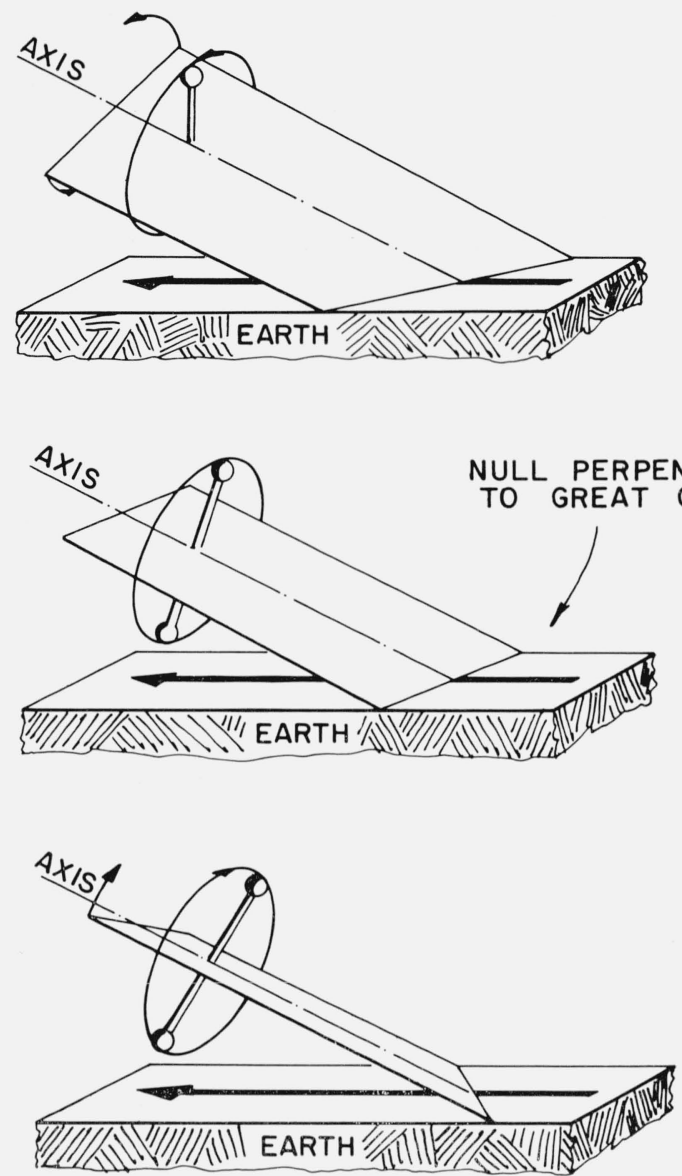

Figure 11. Visualization of null rotation.

These points have values of $\Delta \theta$ up to about 1 or $2 \mathrm{deg}$ and values of $\Delta \eta$ over $8 \mathrm{deg}$. They seem to result from interference between rays that are both close to the great circle bearing and that never come close to each other in elevation, such as perhaps different order $E$-layer rays. The fact that $\Phi$ for this group is near $360 \mathrm{deg}$ means that the nulls are moving in the approximate direction of the transmitter. Such motion would result if the frequency of the higherelevation-angle ray had a larger positive value of Doppler shift than the $2-E$ ray, though it is not so obvious why the $3-E$ shift should always appear to be positive with respect to the $2-E$ shift.

The points in figure $12 \mathrm{~b}$ fairly evenly fill quadrants II and IV and also show a grouping around $\Phi=0 \mathrm{deg}$ that has a number of points in quadrant $I$. The bearing deviation $\Delta \theta$ is generally between 0.5 and 4 $\mathrm{deg}$ and the elevation difference varies from $0 \mathrm{deg}$ up to about 8 or $10 \mathrm{deg}$. The elevation difference may in figures $12 \mathrm{~b}$ and $12 \mathrm{c}$ be negative, corresponding to $1-F$ or $E$ rays, in which case the bearing difference is generally negative also. All that is required for $\Phi$ to lie in quadrants IT or IV is that $\Delta \theta$ and $\Delta \eta$ have the same sign, which will result from a general north to south downward tilt of the reflecting layers. 

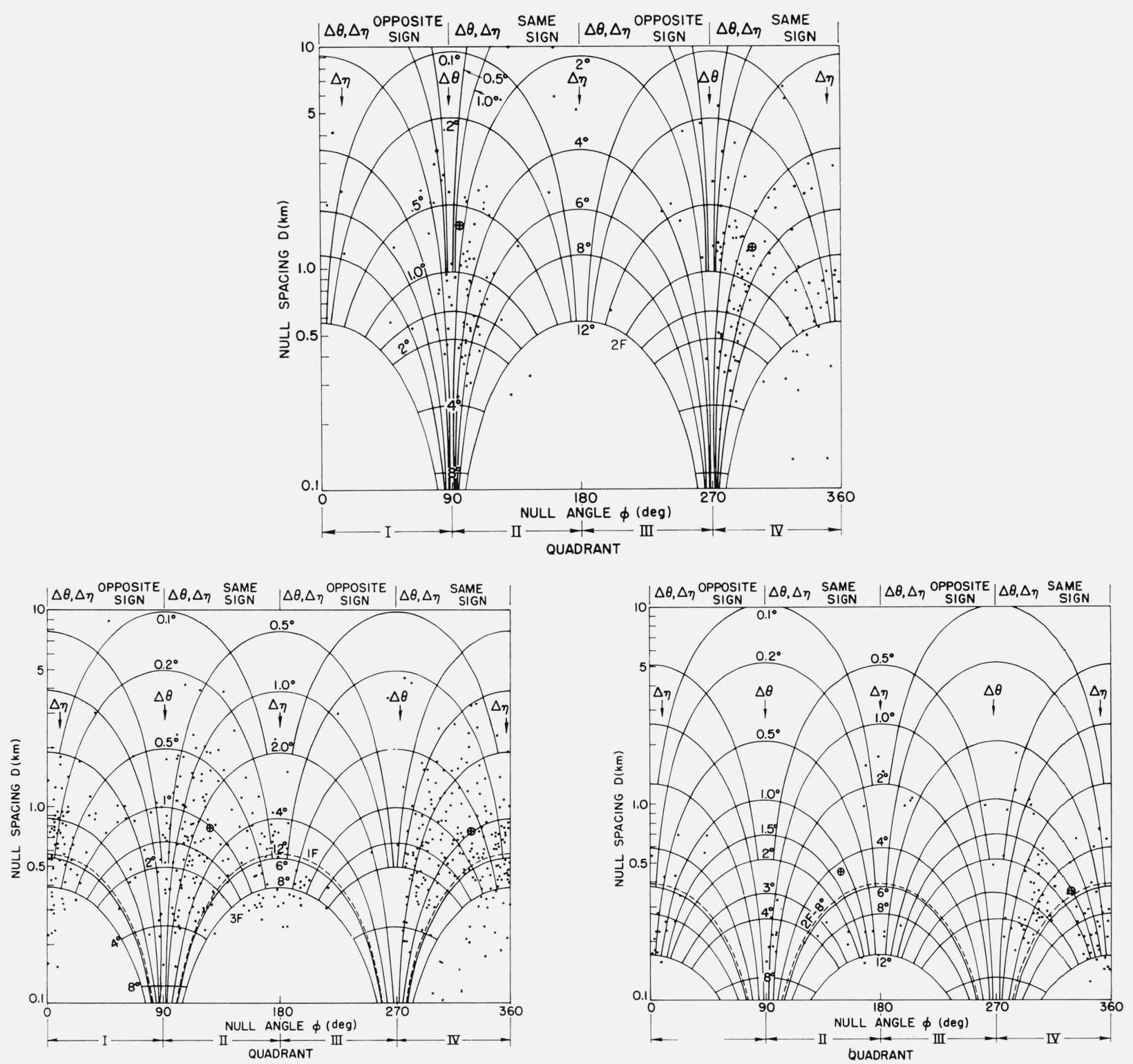

Figure 12. Predicted and observed fading-pattern parameters during periods of different layer propagation.

a. 1-F propagation from Hawaii

b. 2-F propagation from Hawaii

c. $3-\mathrm{F}$ propagation from Hawaii

The $3-F$ scatter diagram, figure $12 \mathrm{c}$, has, as expected, the smallest average values of null spacing and also shows a concentration of $\Phi$ values in the second and fourth quadrants. The splitting of the points in quadrant IV into two groups, leaving the centroid in a region of few points, may have the same significance as in figure 12a. It should be kept in mind that $1-F, 2-F$, or $E$ rays can contribute to the effects observed in the $3-F$ plot, since the criterion for selection was simply the identity of the highest order mode. The laterally deviated rays during times of $3-F$ propagation appear to cluster about $\Delta \theta=3 \mathrm{deg}$ and $\Delta \eta=4 \mathrm{deg}$.
Texas and Puerto Rico data. Figure 13 shows scatter diagrams of the fading pattern parameters observed over the Texas-to-Stanford path. Since the propagation direction was approximately opposite to that from Hawaii, while the lateral ionospheric tilts were estimated to be about the same, elevation and bearing differences between the rays would be expected to have opposite signs. This hypothesis is confirmed by the fact that most of the fading: patterns were observed to lie in quadrants I and III. In addition, a considerable number of points appear on the border between I and IV, indicating periods of little or no ionospheric tilt. The propaga- 


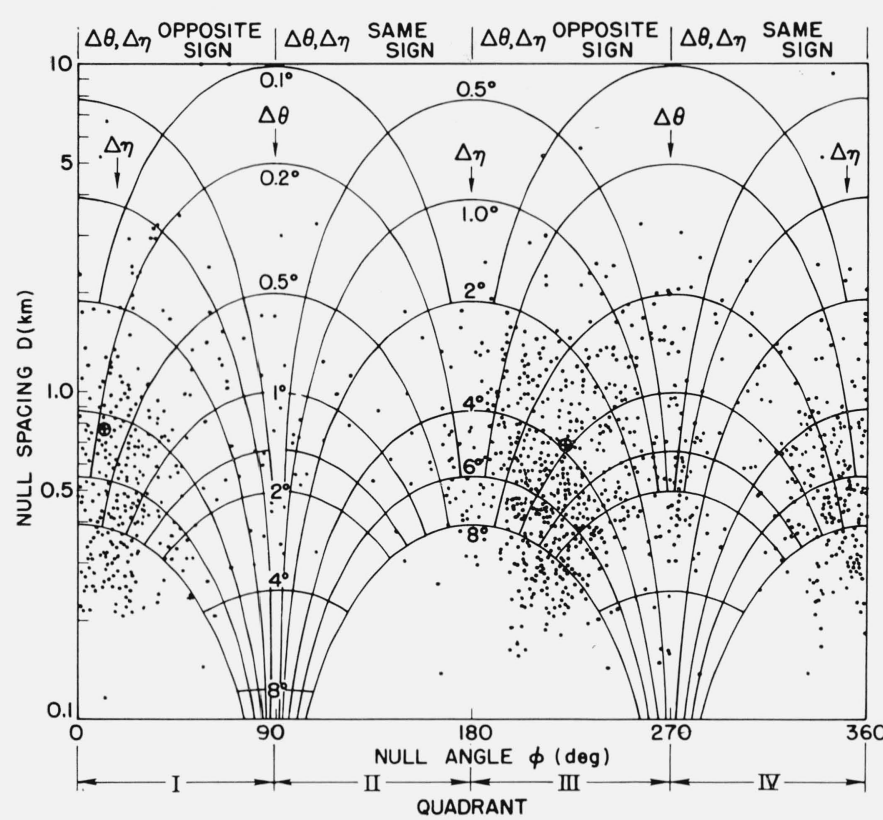

Figure 13. Predicted and observed fading-pattern parameters for all propagation (1-F) from Texas.

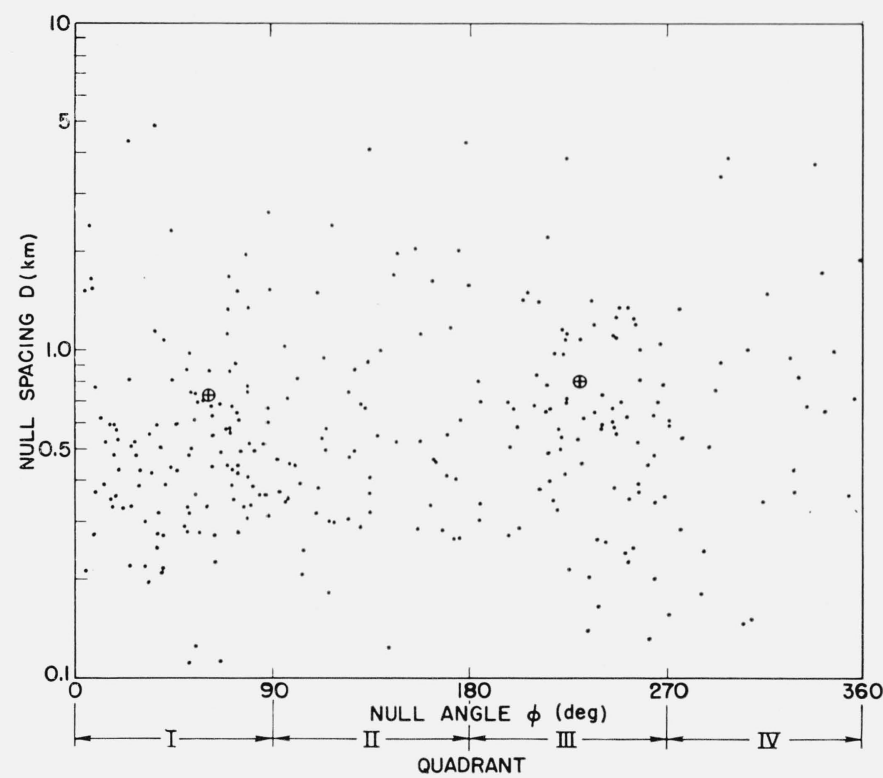

FIGURE 14. Observed fading-pattern parameters (D versus $\Phi$ ) for all propagation from Puerto Rico.

tion from Texas was always by $1-F$ region reflection; $\eta_{0}$ was assumed to be $14 \mathrm{deg}$.

Figure 14 shows the effect of the longer propagation path between Puerto Rico and Stanford. Since several different modes were possible over this path and since no oblique sounder was available to identify them, all the available data are presented on one figure. Though the groups are not as sharply defined as for the other paths, a concentration of values in the first and third quadrants is still apparent.

\subsection{Average Values of Fading Parameters}

\section{a. Orientation of Fading Nulls}

Histograms of the distribution of $\Phi$ as measured on signals propagated over the three paths studied are shown in figure 15 and are summarized in table 2. For each path about 70 percent of the nulls lie in the expected quadrants, though some distributions are biased toward one or the other extremity of the expected quadrant.
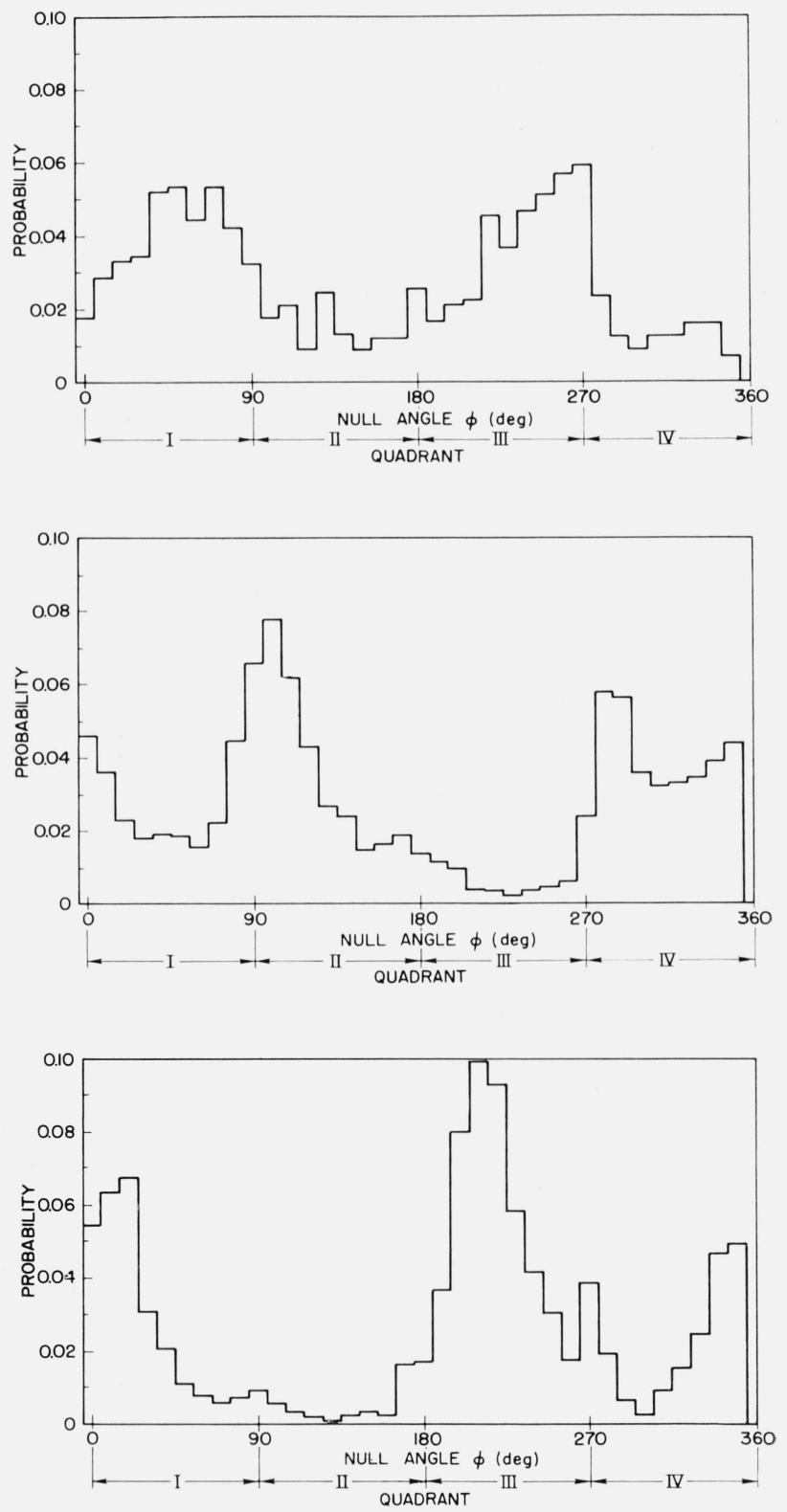

Figure 15. Distribution of all $\Phi$ measurements.

$$
\begin{aligned}
& \text { a. Puerto Rico to Stanford path } \\
& \text { b. Hawaii to Stanford path } \\
& \text { c. Texas to Stanford path }
\end{aligned}
$$


TABle 2. Percentage of $\Phi$ measurements in 90-deg quadrants over different paths

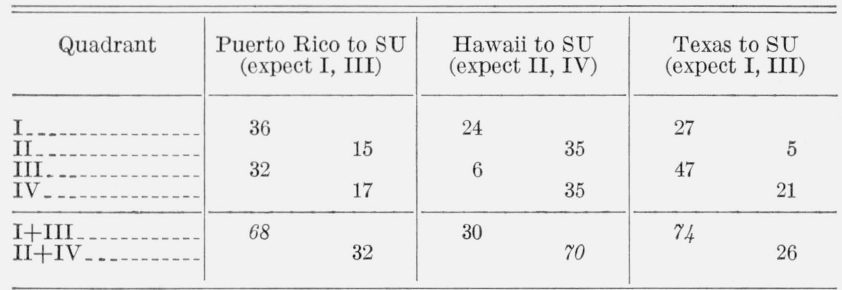

NOTE: $\Phi=0$ corresponds to a null lying perpendicular to the great circle between transmitter and receiver and moving toward the transmitter (see fig. 3 ).

\section{b. Scalar Parameters}

The overall mean value of null spacing, $D$, observed on the fading patterns of signals from Hawaii was $0.88 \mathrm{~km}$, with a standard deviation of $0.98 \mathrm{~km}$. Comparable figures for the signals from Puerto Rico, and Texas are shown in table 3.

TABLE 3. Summary of scalar fading pattern measurements

\begin{tabular}{|c|c|c|c|}
\hline \multirow{2}{*}{ Path } & \multirow{2}{*}{$\begin{array}{l}\text { Number of } \\
\text { measure- } \\
\text { ments }\end{array}$} & Mean & $\begin{array}{l}\text { Standard } \\
\text { deviation }\end{array}$ \\
\hline & & \multicolumn{2}{|c|}{ Spacing $D(\mathrm{~km})$} \\
\hline \multirow[t]{2}{*}{$\begin{array}{l}\text { PR-SU } \\
\text { Hawaii-SU. } \\
\text { Texas-SU... }\end{array}$} & $\begin{array}{r}305 \\
3,506 \\
1,527\end{array}$ & $\begin{array}{r}0.755 \\
.880 \\
.694\end{array}$ & $\begin{array}{r}0.741 \\
.984 \\
.674\end{array}$ \\
\hline & & \multicolumn{2}{|c|}{ Velocity $V(\mathrm{~km} / \mathrm{sec})$} \\
\hline \multirow[t]{2}{*}{$\begin{array}{l}\text { PR-SU } \\
\text { Hawaii-SU. } \\
\text { Texas-SU }\end{array}$} & $\begin{array}{r}899 \\
3,520 \\
1,527\end{array}$ & $\begin{array}{r}0.382 \\
.322 \\
.222\end{array}$ & $\begin{array}{r}0.445 \\
.329 \\
.195\end{array}$ \\
\hline & & \multicolumn{2}{|c|}{ Fading rate $(\mathrm{c} / \mathrm{s})$} \\
\hline $\begin{array}{l}\text { PR-SU } \\
\text { Hawaii-SU. } \\
\text { Texas-SU. }\end{array}$ & $\begin{array}{r}305 \\
3,506 \\
1,527\end{array}$ & $\begin{array}{r}0.644 \\
.476 \\
.388\end{array}$ & $\begin{array}{r}0.304 \\
.351 \\
.262\end{array}$ \\
\hline
\end{tabular}

The difference in numbers of $D$ and $V$ measurements is a result of the presence of fading patterns in which it was possible to find individual nulls that were typical of the sample but that were not adjacent to a sufficiently similar null for a meaningful measurement of $D$ or $F$.

\subsection{Doppler Shift Effects}

A clear example of the difference in fading pattern effects produced by ray geometry and by signal Doppler shift is given in figures 16 and 17 which show fading-pattern data during a reversal of direction of null motion. During the time shown in the figures, $1-F$ upper and lower rays were interfering to produce the observed fading patterns, as was true of virtually all the Texas data. The ray elevations and bearings remained constant during the period; as deduced from the fact that the oblique ionograms showed a constant delay time between the $1-F$ upper

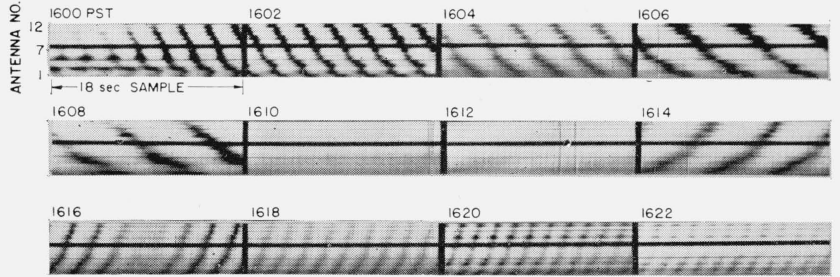

Figure 16. Fading pattern records of 7 October 1963 for the Texas-Stanford path showing a reversal in direction of null motion.

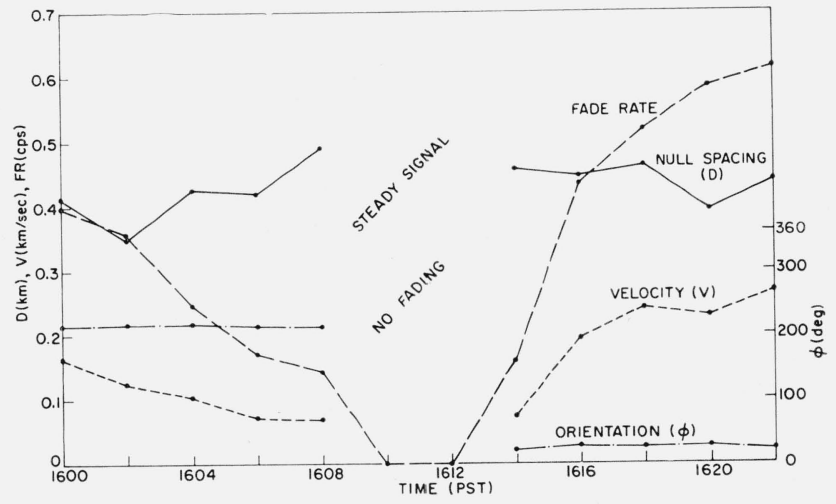

Figure 17. Fading parameters during reversal of null direction.

and lower rays and that the null spacing and orientation, except for the $180 \mathrm{deg}$ shift, remained nearly the same. The fading rate, which is simply the difference in doppler shifts of the two rays, went through a definite zero value at the time of the reversal of null direction.

It can be seen from this sequence of events that the orientation and spacing of nulls in a spatial fading pattern are a function of ray geometry and that the null velocity adjusts itself so as to be consistent with the fading rate determined by the difference in doppler shifts of the two interfering waves. The null patterns typically reversed their direction of motion with a period on the order of $2 \mathrm{hr}$.

\subsection{Fading Pattern Observations During Two Magnetic Storms}

Routine fading-pattern and mode-identification measurements were in progress on the Hawaii-toStanford signal during the moderately severe magnetic storms of 30 April 1963 and 6 June 1963. Both storms produced similar effects on the fading patterns and propagation mode structure. These effects are explained in terms of a description of the average morphology of magnetic storms based on observation of over 100 such storms by Matsushita [1959].

Matsushita shows that, during summer at the latitudes involved in the present experiment (his regions 4,5 , and 6 ) there is a moderate increase in maximum electron density during the first 9 or $10 \mathrm{hr}$ of the storms at the higher latitudes and less or none at the lower. During the next $40 \mathrm{hr}$, there is a large 
decrease in maximum density throughout the region, with the decrease being greater at higher latitudes. There is actually an increase near the geomagnetic equator. The effect of these phenomena on the normally tilted layers of constant ion density is shown in simplified schematic form in figure 18 in which it is assumed that an increase in the maximum electron density of a layer lowers the contours of fixed electron density.

Figure 18 shows that, during the first day of a magnetic storm, there should be less than the normal amount of ionospheric tilt and therefore $\Phi$ for the fading patterns should shift toward 0 and 180 degrees. Since, during this period, the ion density is greater than normal, the existence of modes of more than the usual number of ionospheric reflections should be possible with a resulting decrease in null spacing. During the second day of the storm the tilt may be greater than normal, moving $\Phi$ toward 90 and 270 deg. The lower value of electron density will allow fewer ionospheric reflections, resulting in an increase of null spacing above its normal value.

TABLE 4. Summary of magnetic storm data over HawaiiStanford path

\begin{tabular}{|c|c|c|c|c|c|}
\hline & \multirow{2}{*}{$\begin{array}{l}\text { Average of } \\
\text { Hawaii-Stan- } \\
\text { ford data } \\
\text { (Nov. 2, 1962 } \\
\text { to June 8, } \\
\text { 1963) }\end{array}$} & \multicolumn{2}{|c|}{$\begin{array}{l}\text { Magnetic storm of } \\
30 \mathrm{Apr} .1963\end{array}$} & \multicolumn{2}{|c|}{$\begin{array}{l}\text { Magnetic storm of } \\
6 \text { June, } 1963\end{array}$} \\
\hline & & 30 Apr. & 1 May & 6 June & 7 June \\
\hline $\begin{array}{l}\text { Null spacing } D(\mathrm{~km}) \text { : } \\
\text { Mean } \\
\text { Std. Dev. }\end{array}$ & $\begin{array}{l}0.880 \\
0.984\end{array}$ & $\begin{array}{l}0.780 \\
1.02\end{array}$ & $\begin{array}{l}1.13 \\
1.32\end{array}$ & $\begin{array}{l}0.465 \\
0.722\end{array}$ & $\begin{array}{l}1.27 \\
0.974\end{array}$ \\
\hline $\begin{array}{l}\text { Null velocity } V(\mathrm{~km} / \\
\text { sec): } \\
\text { Mean } \\
\text { Std. Dev }\end{array}$ & $\begin{array}{l}0.322 \\
0.329\end{array}$ & $\begin{array}{l}0.501 \\
0.546\end{array}$ & $\begin{array}{l}0.442 \\
0.405\end{array}$ & $\begin{array}{l}0.246 \\
0.245\end{array}$ & $\begin{array}{l}0.329 \\
0.252\end{array}$ \\
\hline $\begin{array}{l}\text { Fade rate } F(\mathrm{c} / \mathrm{s}): \\
\text { Mean } \\
\text { Std. Dev }\end{array}$ & $\begin{array}{l}0.476 \\
0.351\end{array}$ & $\begin{array}{l}0.859 \\
0.563\end{array}$ & $\begin{array}{l}0.440 \\
0.259\end{array}$ & $\begin{array}{l}0.693 \\
0.408\end{array}$ & $\begin{array}{l}0.282 \\
0.163\end{array}$ \\
\hline $\begin{array}{l}\text { Measurable fades } \\
\text { (percent) } \\
\text { Average value of } K p \\
\text { during } \mathrm{CW} \text { obser- } \\
\text { vations............. }\end{array}$ & 26 & $5+$ & $3+$ & $6-$ & 16 \\
\hline $\begin{array}{l}\text { Highest order prop- } \\
\text { agating mode }\end{array}$ & $3-F$ & $3-F$ & ${ }^{2} 2-F$ & $3-F$ & $1-F$ \\
\hline
\end{tabular}

${ }^{1} \mathrm{Kp}$ is the geomagnetic planetary 3 -hr range index prepared by the Committee on Characterization of Magnetic Disturbances, J. Bartels, Chairman, University, Göttingen, Germany. Values regularly appear under “Geomagnetic and Solar Data" in the Journal of Geophysical Research.

2 Mostly $1-F$.

That these effects occur is shown by the contents of table 4 and figure 19 .

During both magnetic storms the value of null spacing is reduced below normal the first day and rises above normal the second day. This is clearly a result of the fact that on both first days signals were received that had experienced $3-F$ layer reflections whereas the highest order mode observed under undisturbed conditions was usually $2-F$. On both second days most of the signals arrived with only $1-F$ layer reflection and therefore the null spacing was relatively large.

Figure 19 shows that on both first days the null direction was concentrated about 0 and $180 \mathrm{deg}$ and

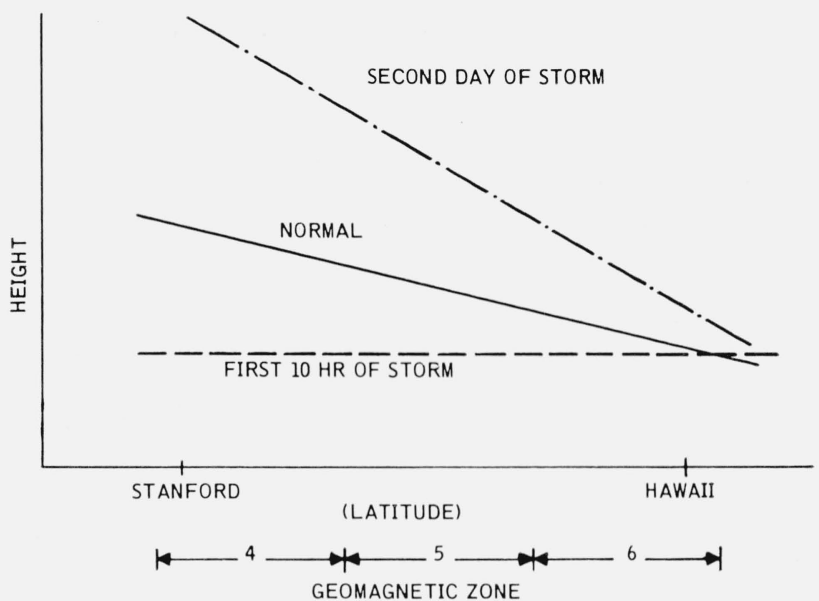

Figure 18. Change in height and slope of a contour of fixed ion density during a magnetic storm.
30 APRI L
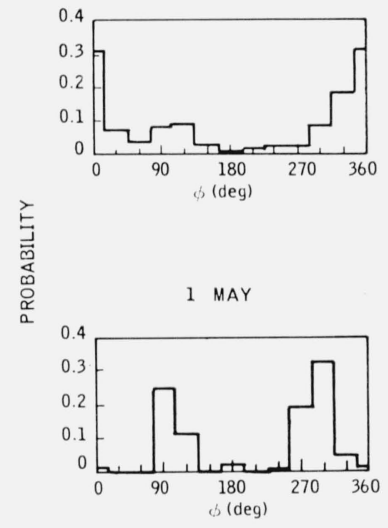

6
Figure 19. Distribution of $\Phi$ measurements during two magnetic storms.

on the second days about 90 and $270 \mathrm{deg}$, presumably for the reasons discussed above.

'The fading rate was higher than normal on both first days and near or below normal on both second days. This could be a consequence of the greater than normal number of ionospheric reflections on the first day and the smaller number on the second day, if the Doppler shift of rays increases with number of hops as suggested by Davies [1962]. A valuable experiment to verify this effect would consist of simultaneous measurements of mode structure, fading rate, and signal Doppler shift.

The fact that the fading during the storm of 30 April 1963 was much more periodic than normal implies that during this storm the total amount of random variation in ionization encountered by the rays was less than normal. 


\section{Practical Applications}

\subsection{Space Diversity Reception}

One obvious practical application of the work described here is illustrated in figure 20 . If, at a particular receiving location, the most likely null patterns were as assumed in the figure, a space-diversity receiving system consisting of antennas $A, B$, and $C$ would be unable to take maximum advantage of the spacing between its elements. Even though the spacing between the elements is $300 \mathrm{~m}$, the effective spacing from the diversity point of view is only 212 $\mathrm{m}$. If either antenna $B$ or $C$ were moved to position $D$, however, the effective spacing would be doubled to $414 \mathrm{~m}$ at no increase in cost. Such effects would, of course, be most noticeable over relatively short paths of only a few thousand kilometers, since the null patterns over such paths show a relatively high degree of periodicity. Nulls in signals propagated over much longer paths would not be expected to be as periodic, though the ionospheric tilts involved should tend to produce similar effects.

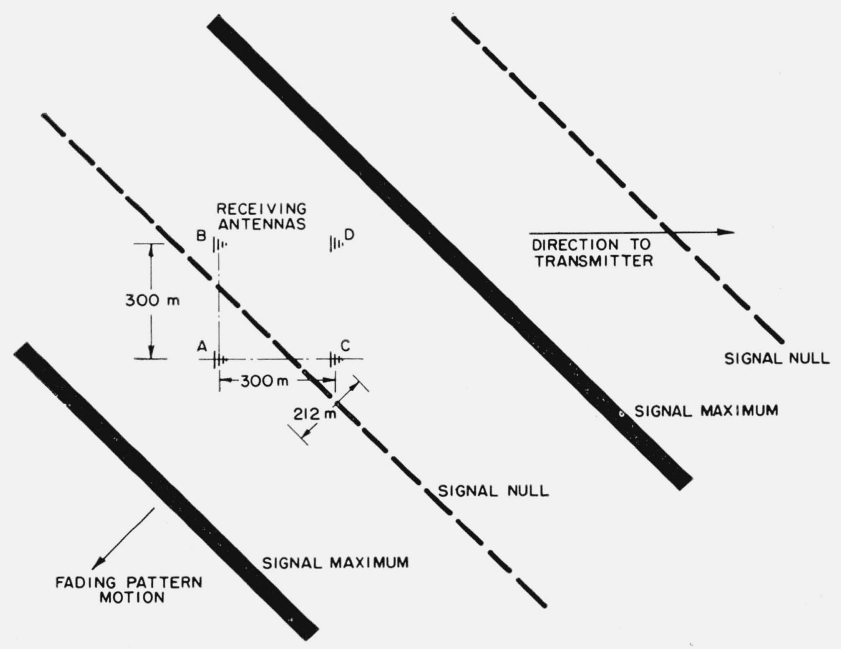

Figure 20. Hypothetical fading pattern showing effect of different space-diversity antenna layouts.

\subsection{Direction Finding}

Direction-finding measurements should be more accurate if made during periods of no ionospheric tilt. Such periods are indicated by values of null direction $\Phi$ near 0 and $180 \mathrm{deg}$. Thus the most precise direction-finding measurements should be made during periods when the fading nulls lie approximately perpendicular to the direction to the unknown transmitter, as obtained during routine directionfinding measurements.

\section{Conclusions}

It appears from these measurements that for 10 to 30 percent of the time, decreasing with increasing path length, the amount of random variation in the ionosphere is small enough to allow the existence of predictable, periodic, destructive interference patterns between rays traveling quite different paths. The mean null spacing is about $0.8 \mathrm{~km}$. The orientation of these fading patterns is strongly influenced by relatively small tilts or gradients in the ionosphere. Results of a practical nature are that space-diversity antenna systems can be improved by disposing antennas along a line perpendicular to the most probable null patterns for any particular receiving site.

The author expresses his appreciation to the Office of Naval Research and the Advanced Research Projects Agency for sponsorship of this research, and to Prof. O. G. Villard, Jr., for his valuable assistance with the experiment and criticism of the manuscript. The transmitting equipment was operated by Prof. Braulio Dueño at the University of Puerto Rico, Prof. Harold Spuhler at the Texas Technological College, and Gerry Hall and Arthur Weekly of Raytheon Co. at Pahoa, Hawaii.

\section{References}

[1] Ames, J. W. (Mar. 1964), Spatial properties of amplitude fading of continuous 17 -Mc radio waves, TR No. 87, SEL-64-022, Radioscience Laboratory, Stanford, Calif.

[2] Croft, T. A., and L. Gregory (Oct. 1963), A fast, versatile ray-tracing program for IBM-7090 digital computers, TR No. 82, SEL-63-107, Radioscience Laboratory, Stanford, Calif.

[3] Davies, K., J. M. Watts, and D. H. Zacharisen (Feb. 1962), A study of $F_{2}$-layer effects as observed with a Doppler technique, J. Geophys. Res. 6\%, No. 2, 601-609.

[4] Hedlund, D. A., and L. C. Edwards (Jan. 1958), Polarization fading over an oblique incidence path, IRE Trans. Ant. Prop. AP-6, 21-25.

[5] Matsushita, S. (Mar. 1959), A study of the morphology of ionospheric storms, J. Geophys. Res. 64, No. 3, $305-321$.

[6] Wright, J. W., L. R. Wescott, and D. J. Brown (May 1961), Mean electron density variations of the quiet ionosphere-4 June 1959, NBS Tech. Note 40-4.

(Paper 68D12-435) 